\title{
Title: Computed tomographic biomarkers in idiopathic pulmonary fibrosis: the future of quantitative analysis
}

Authors: Xiaoping Wu, MD ${ }^{1}$; Grace H. Kim, MS, $\mathrm{PhD}^{2}$; Margaret L. Salisbury MD David Barber, $\mathrm{PhD}^{4}$; Brian J. Bartholmai, MD"; Kevin K. Brown, MD; ; ${ }^{6}$ raig S. Conoscenti, MD ${ }^{7}$; Jan De Backer, $\mathrm{PhD}^{8}$, MBA; Kevin R. Flaherty ${ }^{3}$, MD, MS; James F. Gruden, $M D^{9}$; Eric A. Hoffman, $\mathrm{PhD}^{10}$, Stephen M. Humphries, $\mathrm{PhD}^{11}$; Joseph Jacob, MD ${ }^{12,13}$; Toby M. Maher, MD, PhD ${ }^{14}$; Ganesh Raghu, MD ${ }^{15}$; Luca Richeldi, MD, PhD ${ }^{16}$; Brian D. Ross, PhD ${ }^{17}$; Rozsa Schlenker-Herceg, MD ${ }^{7}$; Nicola Sverzellati, MD ${ }^{18}$; Athol U. Wells, MD ${ }^{14}$; Fernando J. Martinez, MD, MS ${ }^{1}$; David A. Lynch, MBBCh ${ }^{11}$; Jonathan Goldin, MD, $\mathrm{PhD}^{2}$; Simon LF Walsh, $\mathrm{MD}^{19}$

\section{Affiliations:}

${ }^{1}$ Weill Cornell Medicine, Pulmonary and Critical Care Medicine, New York, NY, USA ${ }^{2}$ UCLA School of Medicine, Radiological Science, Los Angeles, CA, USA

${ }^{3}$ University of Michigan Hospital, Pulmonary and Critical Care Medicine, Ann Arbor, MI, USA

${ }^{4}$ University College London, Computer Science, London, UK

${ }^{5}$ Mayo Clinic, Radiology, Rochester, MI, USA

${ }^{6}$ National Jewish Health, Pulmonary, Critical Care and Sleep Medicine, Denver, CO, USA

${ }^{7}$ Boehringer Ingelheim Pharmaceuticals, Inc., Ridgefield, CT, USA

${ }^{8}$ FluidDA nv Groeningenlei, Kontich, BE

${ }^{9}$ Weill Cornell Medicine, Radiology, New York, NY, USA

${ }^{10}$ University of lowa Carver College of Medicine, Radiology, lowa City, IA, USA

${ }^{11}$ National Jewish Health, Radiology, Denver, CO, USA

${ }^{12}$ University College London, Respiratory Medicine, London, UK

${ }^{13}$ University College London, Centre for Medical Image Computing, London, UK

${ }^{14}$ Royal Brompton Hospital, Interstitial Lung Disease Unit, London, UK 
${ }^{15}$ University of Washington Medical Center, Pulmonary and Critical Care Medicine, Seattle, WA, USA

${ }^{16}$ Fondazione Policlinico Universitario A. Gemelli, Universita Cattolica del Sacro Cuore, Rome, IT

${ }^{17}$ University of Michigan Hospital, Radiology, Ann Arbor, MI USA

${ }^{18}$ University of Parma, Radiology, Department of Medicine and Surgery, Parma, IT

${ }^{19}$ Kings College Hospital NHS Foundation Trust, Radiology, London, UK

*Any views expressed in this manuscript represent the personal opinions of the author and not those of Boehringer Ingelheim Pharmaceuticals.

\section{Corresponding author:}

Simon LF Walsh, MD

Department of Radiology

Kings College Hospital NHS Foundation Trust

London, UK

slfwalsh@gmail.com

Author Contributions: Conception and design: XW, GHK, JGG, FJM, and SLFW. Drafting the manuscript for important intellectual content: XW, GHK, MLS, BJB, KKB, CSC, JDB, EAH, SMH, JJ, TMM, NS, AUW, DAL, JGG, and SLFW. Critical review and editing: XW, GHK, MLS, DB, BJB, KKB, CSC, JDB, KRF, JFG, EAH, SMH, JJ, TMM, GR, LR, BDR, RSH, NS, AUW, FJM, DAL, JGG, and SLFW. All authors approved the manuscript. 


\section{Abstract}

Idiopathic pulmonary fibrosis (IPF) is a chronic lung disease with great variability in disease severity and rate of progression. The need for a reliable, sensitive, and objective biomarker to track disease progression and response to therapy remains a great challenge in IPF clinical trials. Over the past decade, quantitative computed tomography (QCT) has emerged as an area of intensive research to address this need. We have gathered a group of pulmonologists, radiologists and scientists with expertise in this area to define the current status and future promise of this imaging technique in the evaluation and management of IPF. In this Pulmonary Perspective, we review the development and validation of six computer-based QCT methods and offer insight into the optimal use of an imaging-based biomarker as a tool for prognostication, prediction of response to therapy, and potential surrogate endpoint in future therapeutic trials. 


\section{Introduction}

Idiopathic pulmonary fibrosis (IPF) is the classic fibrosing interstitial lung disease (ILD). While inexorably progressive, its natural history is inconsistent and unpredictable (1, 2).This variability in the rate and severity of disease progression makes prognostication for individual patients challenging and creates significant barriers to efficient drug development. Validation of a sensitive, reproducible and objective biomarker that accurately tracks disease progression and response to therapy would be of enormous benefit. High-resolution computed tomography (HRCT) of the chest is routinely performed in patients with suspected fibrotic lung disease and is widely available, making it a promising target for biomarker research (3). Although there is ample evidence that HRCT provides prognostic information in IPF, qualitative visual assessment is limited by inter-observer variability (4). In contrast, computer-based methods for quantifying disease on HRCT could provide rapid, objective measurement of disease extent and change over time. We convened a group of chest radiologists and pulmonary clinicians with IPF expertise, scientists with expertise in computational image analysis, and key individuals from the pharmaceutical industry to address the optimal approach to developing image-based biomarkers for diagnosis, prognosis and monitoring of response to therapy in IPF.

\section{Background}

\section{Imaging Endpoints and Biomarkers in IPF}

The Biomarkers Definitions Working Group defines a clinical endpoint as a variable that reflects how a patient feels, functions, or survives $(5,6)$. The past three decades of IPF 
clinical trial design have struggled to find a clinical primary endpoint that can be routinely used. Although all-cause mortality is a well-defined, reliable, and easy to measure primary endpoint, its use in IPF is limited due to low event rates (7). Therefore, in the absence of an ideal endpoint such as mortality, the substitution of a validated biomarker for a clinical endpoint (i.e. a surrogate endpoint) that can reliably predict the effect of the therapy can significantly improve the efficiency of IPF clinical trials (8-10).

While quality of life and functional status instruments are predictive of mortality and show promise as potential biomarkers, these measures may not reflect therapeutic impact commensurate with survival (6). Forced vital capacity (FVC) is widely considered an accepted surrogate endpoint in IPF clinical trials and is routinely used as a primary endpoint. However, it is prone to missing data, may miss important treatment effects, and as currently approved therapies affect its rate of decline, its use in future trials may be less compelling (11-13). Quantitative computed tomography (QCT) can be reproducibly performed across the spectrum of disease severity. Currently available data support the ability of QCT to measure baseline disease severity and progression making it potentially an attractive surrogate endpoint $(14,15)$.

\section{Challenges in Qualifying a Biomarker}

We seek to establish the clinical value of existing imaging-based biomarkers as prognostic factors (the effects of patient-specific or IPF characteristics on patient outcome), predictive factors (the effects of treatment on IPF), and surrogate endpoints in the setting of IPF (16). As a prognostic factor it is objectively measurable and might provide information on the likely outcome of IPF in an untreated individual. As a 
predictive factor, it might provide information on the likely benefit from treatment (either in terms of physiologic outcome or survival). Such predictive factors can be used to identify subpopulations of patients or specific phenotypes that are most likely to benefit from a given therapy.

\section{Imaging Biomarker Development and Validation}

In the development and qualification of an imaging biomarker, there are three important phases: (1) development (including training of classifiers), (2) analytic validation (determination of cut points, assessment of reproducibility, and evaluation against radiologist measurements), and (3) clinical validation in which the system and its cut points are fixed and it is evaluated against outcomes in new clinical trial data. In the development phase, a supervised classification model is usually constructed using regions of interest with parenchymal abnormalities identified and classified visually by an expert thoracic radiologist. Test validation studies are then performed to estimate the variation of measurement and clarify the cut points for the intended use of the proposed biomarker. Clinical utility is tested in retrospective then prospective studies to show evidence that the effect of a therapeutic intervention on a clinical endpoint (e.g. mortality) can reliably be predicted by QCT. The final step in this process is qualification of the biomarker by regulatory bodies, such as the FDA, for use in therapeutic trials and routine clinical practice (17). To date, none of the available QCT methods have completed this process. 


\section{Current Imaging Analysis Methods for IPF Evaluation}

\section{Imaging Protocols}

Standardized imaging acquisition is crucial for QCT (18). Volumetric acquisition with contiguous thin section reconstruction is important, with slice thickness usually around 1 $\mathrm{mm}$. Since the depth of inspiration can be a major source of variation, coaching the patient to comply with standardized breathing instructions is critical. Computed tomography (CT) radiation dose used for the acquisition is variable, but can be relatively low, and further reduced by dose modulation. For image reconstruction, a relatively "soft" kernel is used to avoid excessive noise; sharper acquisitions can also be acceptable if a denoising or kernel normalization technique is used (19). Iterative reconstruction techniques are not recommended until the effects of this reconstruction on textural analysis can be clearly understood. To ensure that QCT measurements are comparable, patients should be imaged using the same technique, ideally on the same CT scanner, at all timepoints. The utility of CT phantom acquisition (20) in clinical trials has not been established but may assist with machine calibration and correct implementation of an acquisition protocol before data collection begins.

\section{Visual Semi-Quantitative Scoring}

A CT pattern of usual interstitial pneumonia (UIP) is associated with higher mortality in fibrotic lung disease (21-23). Additionally, the extent of fibrosis on HRCT has been consistently linked to mortality in IPF in numerous studies $(4,24-27)$. Most outcome studies involving HRCT in IPF have focused on the ability of baseline HRCT patterns to predict outcome, but few have evaluated the ability of serial HRCT changes over a 
specific follow-up period to predict outcome. Semi-quantitative HRCT evaluation is prone to inter- and intra-observer variability and may be too insensitive to capture clinically important short-term changes (28).

Despite the large and consistent body of literature indicating a prognostic role for HRCT in IPF, HRCT-based biomarkers are neither routinely used in clinical practice nor incorporated as clinical endpoints in therapeutic trials for several reasons. First, visual assessment of HRCT patterns is subjective, with significant inter-observer variation, even among expert radiologists. For example, honeycombing has consistently demonstrated prognostic significance in many studies over the past 15 years (29-33) yet the inter-observer agreement for the presence of this pattern is moderate at best $(4$, $31,34)$. Second, it is not yet clear how HRCT pattern and extent can help inform management decisions in an individual patient. Unlike in oncology, where an imagebased disease stage maps directly to a management strategy, CT-based staging is not yet routinely used in IPF, although attempts have been made to do so (35-37).

\section{Computer-based Quantitative Scoring Systems}

Although computer assisted diagnosis (CAD) algorithms for classifying HRCT patterns have existed for decades (38), recent advances in computer processing power have enabled a groundswell of renewed interest in computer-assisted HRCT image analysis. In recent years, some of these tools have been used to analyze CT imaging data in clinical trials both retrospectively and prospectively. Below is a summary of some of the available computer-based methods for quantifying disease on HRCT that have been used to evaluate clinical trial populations in IPF (Table 1). There is currently no 
consensus regarding the optimal method for QCT analysis and this review should not be interpreted as a comparison of their strengths and limitations.

\section{Histogram Kurtosis/Density Measures}

The Hounsfield unit (HU) scale is a measurement of relative densities (attenuation) determined by CT. In the lung parenchyma, CT attenuation measured in $\mathrm{HU}$, is determined by the relative amounts of air, soft tissue, and blood in each volume element (voxel). The CT histogram provides a distribution of HU for an individual CT image or for the entire lung, permitting calculation of mean lung attenuation, variance, skewness, entropy, and kurtosis. Kurtosis describes the sharpness of the histogram peak and is inversely proportional to the thickness of the two tails of the histogram. Since lung fibrosis or inflammation causes an increase in the amount of soft tissue in the lung, it will increase mean lung attenuation, and thereby decrease the sharpness of the histogram peak (kurtosis) and the degree of leftward skewness of the curve (Figure 1). Mean lung attenuation, skewness, and kurtosis can therefore be used as measures of the extent of lung fibrosis. Generally, a large value of kurtosis indicates mild fibrosis whereas low kurtosis (i.e. close to 0 or negative) indicates moderate to severe fibrosis (39). Kurtosis and skewness of a histogram are known to be correlated with changes in FVC and overall survival in patients with $\operatorname{IPF}(15,40)$.

\section{Adaptive Multiple Features Method (AMFM)}

The Adaptive Multiple Feature Method (AMFM) is a computer-based texture analysis tool that quantifies lung parenchymal patterns on CT. During development, the AMFM 
tool was trained on various parenchymal patterns using $31 \times 31$ pixel regions of interest (image patches) extracted from CT images (41-43). Ground truth labeling of image patches was provided by the consensus vote of a group of experienced observers (43). During training, the AMFM narrows the texture in a training set image patch to a small number of optimal features for classification which are then applied to a test set via a Bayesian classifier. The kappa statistic of agreement between the regions, for which most observers agreed on the pattern type, versus the AMFM tool was 0.62 (43). This technique has been extended to 3 -dimensional texture analysis $(44,45)$ and used to explore the association between the AMFM regional characterization of the lung and outcomes in IPF patients (46) (Figure 2). Among patients with IPF enrolled in clinical therapeutic trials, both visual and AMFM measurement of baseline extent of mixed ground glass and reticular (GGR) densities predicted subsequent disease progression (defined as composite death, hospitalization, or $>10 \%$ FVC decline), independent of baseline age, gender, and FVC. Additionally, post-baseline change in GGR correlated with post-baseline change in FVC. The authors concluded that the AMFM provides an automated method of supporting existing prognostic markers and can enrich a study population with subjects at greatest risk of disease progression. A challenge, to date, with the application of the AMFM is the alteration of texture by scanning protocols. Legacy data used in the testing of the AMFM to date has required the use of a mixture of scan protocols and poor control of lung volume. More recent multi-center studies have established cross manufacturer protocols that serve to more closely align image characteristics (47). 


\section{CALIPER}

The automated lung parenchymal characterization by CALIPER (Computer-Aided Lung Informatics for Pathology Evaluation and Rating) uses a computer-vision based technique that includes volumetric local histogram and morphologic analysis to provide quantitative assessment of pulmonary parenchymal disease on HRCT data. This process automatically labels each pixel of a volumetric HRCT as belonging to one of 7 specific parenchymal features: normal, ground glass opacity, reticular density, honeycombing and mild, moderate or severe low attenuation areas. The CALIPER classifier of lung parenchyma was developed from training sets of pathologically proven ILD and control subjects' HRCT data obtained for the Lung Tissue Research Consortium (LTRC) (48) (Figure 3). Although technical features of acquisition and reconstruction are important to reproducibility of quantitative measures, the CALIPER measures have been shown to be reproducible and robust across a wide variety of acquisition and reconstruction techniques, including low (about 1-2mSv) and ultra-low ( 0.1 to $0.3 \mathrm{mSv}$ ) dose CT techniques with both filtered-back-projection and iterative reconstruction techniques (49).

The CALIPER tool has been used retrospectively on thousands of datasets from multiple institutions and for prospective analysis of approximately 3000 HRCT scans acquired for the LTRC. It has been successfully used to predict survival and future physiologic change (such as FVC decline) in a variety of fibrotic lung diseases such as IPF, fibrotic non-specific interstitial pneumonia (NSIP), hypersensitivity pneumonitis (HP), unclassifiable ILD, and mixed processes such as combined pulmonary fibrosis and emphysema (50-55). Furthermore, a CALIPER-derived HRCT measure of 
"pulmonary vascular-related structures" (PVRS) provides highly discriminative prognostic information in IPF, connective tissue disease related ILD, HP and unclassifiable ILD. Using additional automated clustering, the CALIPER characterization has been used to phenotype disease and automatically stratify subjects into sub-groups with prognostic value in 1322 LTRC scans $(56,57)$. CALIPER has also been utilized prospectively in a double-blind, placebo-controlled, phase 2 clinical trial of a novel antifibrotic drug for IPF, using spirometrically-controlled HRCT at baseline and 28 weeks. The mean change in lung volumes and percent interstitial lung abnormalities (sum of ground glass, reticular densities and honeycombing) was evaluated as a secondary endpoint (58).

\section{Quantitative Lung Fibrosis (QLF)}

QLF is part of a panel of measures including quantitative honeycomb (QHC), ground glass (QGG) and composite interstitial lung disease (QILD) scores (59). In the discovery phase, the denoised texture features and support vector machine (SVM) demonstrated robustness in quantitative features across different scanner models and in classifying normal patterns (60). In validation, a five-step process was automated: (1) denoise; (2) voxel sampling; (3) calculate texture features; (4) run SVM classifier; and (5) output scores as ratios (percentage) or volumes (milliliters). Analytic validation has been reported: QLF demonstrated a good performance with visual scoring area under the curve (AUC) of 0.96 for detection and quantitation of diffuse lung disease, a short-term repeatability coefficient $(\mathrm{RC})$ of $0.4 \%$ for whole lung and $2 \%$ for the most severe lobe within a subject $(39,60,61)$. The QLF classifier has utilized robustness-driven feature 
selection to improve robustness against slice thickness, reconstruction kernel, and tube current without sacrificing performance. Cut points based on the repeatability measures have been frozen and QLF and QILD extent at baseline are prognostic of survival and FVC impairment (Figure 4). As surrogate outcomes, QLF and QILD scores have been clinically utilized in 2,059 HRCT scans from 1,136 subjects in 7 IPF clinical trials showing both treatment efficacy and correlation with FVC change.

Data-driven Textural Analysis (DTA)

DTA is based on unsupervised feature learning and is implemented as a simple convolutional neural network (CNN). The convolutional weights are pre-computed in an initial clustering process on a large collection of unlabeled images (62). The network is trained as a binary classifier using radiologist-labeled regions of interest (ROIs) demonstrating normal parenchyma and UIP patterns. DTA fibrosis score is calculated as the number of ROls classified as fibrotic divided by the total number of ROls sampled from a lung segmentation volume (Figure 5).

Analytic validation in 280 subjects enrolled in IPF Network trials showed that extent of fibrosis measured by DTA correlates with physiologic impairment at baseline (FVC percentage predicted $\rho=-0.60, p<0.001$; diffusing capacity for carbon monoxide (DLCO) percentage predicted $\rho=-0.68, p<0.001)$. Responsiveness was tested in a subset of 72 subjects with 15-month follow-up HRCT. Change in DTA score was correlated with change in FVC percentage predicted $(\rho=-0.41, p<0.001)$ and DLCO percentage predicted $(\rho=-0.40, p<0.001)$. Receiver Operating Characteristic (ROC) analysis indicated that an increase in DTA score of $5.5 \%$ at follow-up identified subjects 
who experienced a $5 \%$ absolute decline in FVC percentage predicted (63). In a separate retrospective cohort study of 501 IPF subjects enrolled in an interventional clinical trial, increase in baseline DTA score was associated with increased risk of disease progression and all-cause hospitalization (unpublished data).

\section{Functional Respiratory Imaging (FRI)}

FRI is a combination of low-dose HRCT scans taken at inspiration and expiration, and computer-based flow simulations. The data acquisition procedure includes respiratory gating using a handheld spirometer to ensure correct and repeatable lung volumes (64). $\mathrm{FRI}$ enables regional quantification of lung structure and function and is validated in obstructive lung diseases through comparisons with conventional lung function measures, isotope-based techniques, hyperpolarized helium, exercise tolerance and patient reported outcomes (65-67). Test/retest data and repeated baseline scans show very low variability (1-3\%) for airway volumes, blood vessel volumes and airway resistances $(68,69)$. This low variability is due to the rigorously controlled and respiratory-gated way HRCT scans are obtained, in combination with a standardized 3D reconstruction of the anatomical structures. FRI enables regional quantification of lung structure and function using standardized 3D reconstruction of the anatomical structures (65) (Figure 6). By focusing on the anatomy (e.g. airway and blood volumes) rather than individual voxels, the variability induced by noise or reconstruction algorithms associated with low dose HRCT scans can be reduced.

Recent studies in IPF showed that disease progression, as determined by FVC decline, is associated with a reduction in CT measured lung volumes $\left(R^{2}=0.80\right.$, 
$p<0.001)$ and an increase in relative airway volumes $\left(R^{2}=0.29, p<0.001\right)$. Changes in FVC are correlated with changes in lung volumes $\left(R^{2}=0.18, p<0.001\right)$ and changes in relative airway caliber $\left(R^{2}=0.15, p<0.001\right)(70)$. Lobe and airway volumes can already be significantly affected by IPF while conventional measures such as FVC remain within the normal (healthy) range (71). IPF disease progression manifests itself heterogeneously in terms of FRI parameters, with the lower lobes consistently more affected than the upper lobes. In a recent small drug trial (NCT02738801) using a novel autotaxin inhibitor, FVC showed a positive but non-significant signal of $95 \mathrm{ml}$ between a treatment and placebo arm after 12 weeks of treatment. FRI parameters confirmed the treatment signal with statistical significance (unpublished data). While FRI is a promising technique, additional studies need to be done to further utilize FRI as a standard drug development tool and to determine minimal clinically important difference (MCID).

\section{Advantages of QCT}

Visual CT features (72), derived from two-dimensional interspaced HRCT imaging in the 1980s (73-76), were primarily designed to provide qualitative information that aided diagnosis. As the focus of CT analysis in ILD moves to prognostication on volumetric baseline and longitudinal CTs, the precision, sensitivity and absence of inter-observer variability associated with QCT have made it an increasingly attractive substitute for visual CT analysis. Quantifying subtle changes in CT features using computer analysis is likely to play an important role in the identification of treatment efficacy in an era of newly emerging drug therapies in fibrosing lung disease. 
QCT-derived features have outperformed visual CT variables in predicting outcome across several fibrosing lung diseases with diverse radiographic patterns, demonstrating its utility is not limited to the usual interstitial pneumonia pattern $(57,77$, 78). Additionally, interrogation of three-dimensional datasets by advanced computer vision and deep learning algorithm techniques may also permit identification of novel biomarkers of disease and prognostic CT features. Rapid and reproducible QCT analysis will likely become increasingly important in following subjects with interstitial lung abnormalities identified incidentally on CT, or during lung cancer screening (79-81).

\section{Disadvantages of QCT}

QCT has several limitations. First, most published approaches involve segmentation and feature extraction based on lung density (measured in $\mathrm{HU}$ ), which is heavily influenced by CT dose, slice thickness, and reconstruction kernel, including new iterative reconstructions (59). Second, patient-related factors such as inspiratory volume/effort can significantly impact QCT feature characterization. Thorough coaching of patients regarding inspiratory effort and timing, or spirometric control of studies would greatly facilitate reproducibility of results (82) but would significantly increase the complexity of performance in routine clinical practice. Establishing limits of variation, and possibly adjustment for lung volume, may help to resolve this limitation (83). Third, the availability of a non-contrast, volumetric thin high-resolution CT dataset with a CT kernel that does not alter local $\mathrm{HU}$ accuracy is essential to accurate feature extraction. This may limit the utility of QCT in retrospective CT datasets, as clinical scans 
commonly are reconstructed with parameters that utilize edge-enhancing algorithms to increase the visual conspicuity of some pulmonary features.

\section{Clinical Application of an Image-based Biomarker}

The immediate applicability of QCT relates to its potential role in clinical trials. Its use may be considered in the following clinical settings: to stratify patients by disease severity, with theoretical advantages over pulmonary function tests (avoiding the confounding effect of the normal range) and visual HRCT scoring (avoiding interobserver variation), and as a longitudinal predictor of early mortality. Validation would require that serial $\mathrm{QCT}$ predict mortality more accurately than serial FVC.

\section{Summary}

There is an urgent need to develop sensitive, reproducible and objective biomarkers in IPF that can be used to monitor disease progression and therapeutic response. QCT provides an objective measure of disease extent and an opportunity to detect subtle disease progression. Therefore, understandably, QCT has been the focus of intensive biomarker research over the past decade. However, despite a growing body of literature demonstrating the potential of QCT, several questions remain unanswered. First, it is unclear if QCT can predict response to therapy using baseline data in an individual patient with IPF (i.e. QCT is un-proved as a predictive factor). Second, QCT has not been shown to reliably identify treatment failure early in a trial of therapy. While serial QCT has been applied in clinical trials with interesting results, additional prospective biomarker studies will need to be performed to show that progression of fibrosis by QCT can be used as a surrogate outcome biomarker. 


\section{Acknowledgements:}

The authors would like to thank Three Lakes Partners for their support of this manuscript and the Open Source Imaging Consortium.

\section{References}

1. Ley B, Collard HR, King TE, Jr. Clinical course and prediction of survival in idiopathic pulmonary fibrosis. Am J Respir Crit Care Med 2011; 183: 431-440.

2. Fernandez Perez ER, Daniels CE, Schroeder DR, St Sauver J, Hartman TE, Bartholmai BJ, Yi ES, Ryu JH. Incidence, prevalence, and clinical course of idiopathic pulmonary fibrosis: a population-based study. Chest 2010; 137: 129137.

3. Hansell DM, Goldin JG, King TE, Jr., Lynch DA, Richeldi L, Wells AU. CT staging and monitoring of fibrotic interstitial lung diseases in clinical practice and treatment trials: a position paper from the Fleischner Society. Lancet Respir Med 2015; 3: 483-496.

4. Lynch DA, Godwin JD, Safrin S, Starko KM, Hormel P, Brown KK, Raghu G, King TE, Jr., Bradford WZ, Schwartz DA, Richard Webb W, Idiopathic Pulmonary Fibrosis Study G. High-resolution computed tomography in idiopathic pulmonary fibrosis: diagnosis and prognosis. Am J Respir Crit Care Med 2005; 172: 488-493.

5. Biomarkers Definitions Working G. Biomarkers and surrogate endpoints: preferred definitions and conceptual framework. Clin Pharmacol Ther 2001; 69: 89-95.

6. Raghu G, Collard HR, Anstrom KJ, Flaherty KR, Fleming TR, King TE, Jr., Martinez FJ, Brown KK. Idiopathic pulmonary fibrosis: clinically meaningful primary 
endpoints in phase 3 clinical trials. Am J Respir Crit Care Med 2012; 185: 10441048.

7. King TE, Jr., Albera C, Bradford WZ, Costabel U, du Bois RM, Leff JA, Nathan SD, Sahn SA, Valeyre D, Noble PW. All-cause mortality rate in patients with idiopathic pulmonary fibrosis. Implications for the design and execution of clinical trials. Am J Respir Crit Care Med 2014; 189: 825-831.

8. de Benedictis FM, Guidi R, Carraro S, Baraldi E, Excellence TENo. Endpoints in respiratory diseases. Eur J Clin Pharmacol 2011; 67 Suppl 1: 49-59.

9. Katz R. Biomarkers and surrogate markers: an FDA perspective. NeuroRx 2004; 1 : 189-195.

10. Temple R. Are surrogate markers adequate to assess cardiovascular disease drugs? JAMA 1999; 282: 790-795.

11. Karimi-Shah BA, Chowdhury BA. Forced vital capacity in idiopathic pulmonary fibrosis--FDA review of pirfenidone and nintedanib. N Engl J Med 2015; 372: 1189-1191.

12. Wells AU. Forced vital capacity as a primary end point in idiopathic pulmonary fibrosis treatment trials: making a silk purse from a sow's ear. Thorax 2013; 68: 309-310.

13. Ley B. Clarity on Endpoints for Clinical Trials in Idiopathic Pulmonary Fibrosis. Ann Am Thorac Soc 2017; 14: 1383-1384.

14. Hartley PG, Galvin JR, Hunninghake GW, Merchant JA, Yagla SJ, Speakman SB, Schwartz DA. High-resolution CT-derived measures of lung density are valid indexes of interstitial lung disease. J Appl Physiol (1985) 1994; 76: 271-277. 
15. Best AC, Lynch AM, Bozic CM, Miller D, Grunwald GK, Lynch DA. Quantitative CT indexes in idiopathic pulmonary fibrosis: relationship with physiologic impairment. Radiology 2003; 228: 407-414.

16. Italiano A. Prognostic or predictive? It's time to get back to definitions! J Clin Oncol 2011; 29: 4718; author reply 4718-4719.

17. Qualification Process for Drug Development Tools. In: Services USDoHaH, editor. Silver Spring, MD; 2014.

18. Newell JD, Jr., Sieren J, Hoffman EA. Development of quantitative computed tomography lung protocols. J Thorac Imaging 2013; 28: 266-271.

19. Gallardo-Estrella L, Lynch DA, Prokop M, Stinson D, Zach J, Judy PF, van Ginneken B, van Rikxoort EM. Normalizing computed tomography data reconstructed with different filter kernels: effect on emphysema quantification. Eur Radiol 2016; 26: 478-486.

20. Sieren JP, Newell JD, Judy PF, Lynch DA, Chan KS, Guo J, Hoffman EA. Reference standard and statistical model for intersite and temporal comparisons of CT attenuation in a multicenter quantitative lung study. Med Phys 2012; 39: $5757-5767$.

21. Kim EJ, Elicker BM, Maldonado F, Webb WR, Ryu JH, Van Uden JH, Lee JS, King TE, Jr., Collard HR. Usual interstitial pneumonia in rheumatoid arthritisassociated interstitial lung disease. Eur Respir J 2010; 35: 1322-1328.

22. Flaherty KR, Thwaite EL, Kazerooni EA, Gross BH, Toews GB, Colby TV, Travis WD, Mumford JA, Murray S, Flint A, Lynch JP, 3rd, Martinez FJ. Radiological 
versus histological diagnosis in UIP and NSIP: survival implications. Thorax 2003; 58: 143-148.

23. Chiba S, Tsuchiya K, Akashi T, Ishizuka M, Okamoto T, Furusawa H, Tateishi T, Kishino M, Miyazaki Y, Tateishi U, Takemura T, Inase N. Chronic Hypersensitivity Pneumonitis With a Usual Interstitial Pneumonia-Like Pattern: Correlation Between Histopathologic and Clinical Findings. Chest 2016; 149: 1473-1481.

24. Edey AJ, Devaraj AA, Barker RP, Nicholson AG, Wells AU, Hansell DM. Fibrotic idiopathic interstitial pneumonias: HRCT findings that predict mortality. Eur Radiol 2011; 21: 1586-1593.

25. Mogulkoc N, Brutsche MH, Bishop PW, Greaves SM, Horrocks AW, Egan JJ, Greater Manchester Pulmonary Fibrosis C. Pulmonary function in idiopathic pulmonary fibrosis and referral for lung transplantation. Am J Respir Crit Care Med 2001; 164: 103-108.

26. Gay SE, Kazerooni EA, Toews GB, Lynch JP, 3rd, Gross BH, Cascade PN, Spizarny DL, Flint A, Schork MA, Whyte RI, Popovich J, Hyzy R, Martinez FJ. Idiopathic pulmonary fibrosis: predicting response to therapy and survival. $A m \mathrm{~J}$ Respir Crit Care Med 1998; 157: 1063-1072.

27. Sumikawa H, Johkoh T, Colby TV, Ichikado K, Suga M, Taniguchi H, Kondoh Y, Ogura T, Arakawa H, Fujimoto K, Inoue A, Mihara N, Honda O, Tomiyama N, Nakamura H, Muller NL. Computed tomography findings in pathological usual interstitial pneumonia: relationship to survival. Am J Respir Crit Care Med 2008; 177: 433-439. 
28. Flaherty KR, Mumford JA, Murray S, Kazerooni EA, Gross BH, Colby TV, Travis WD, Flint A, Toews GB, Lynch JP, 3rd, Martinez FJ. Prognostic implications of physiologic and radiographic changes in idiopathic interstitial pneumonia. Am J Respir Crit Care Med 2003; 168: 543-548.

29. Wells AU, Hansell DM, Rubens MB, Cullinan P, Black CM, du Bois RM. The predictive value of appearances on thin-section computed tomography in fibrosing alveolitis. Am Rev Respir Dis 1993; 148: 1076-1082.

30. Sundaram B, Gross BH, Martinez FJ, Oh E, Muller NL, Schipper M, Kazerooni EA. Accuracy of high-resolution CT in the diagnosis of diffuse lung disease: effect of predominance and distribution of findings. AJR Am J Roentgenol 2008; 191 : 1032-1039.

31. Goldin J, Elashoff R, Kim HJ, Yan X, Lynch D, Strollo D, Roth MD, Clements P, Furst DE, Khanna D, Vasunilashorn S, Li G, Tashkin DP. Treatment of scleroderma-interstitial lung disease with cyclophosphamide is associated with less progressive fibrosis on serial thoracic high-resolution CT scan than placebo: findings from the scleroderma lung study. Chest 2009; 136: 1333-1340.

32. Akira M, Inoue $\mathrm{Y}$, Arai T, Okuma T, Kawata Y. Long-term follow-up high-resolution CT findings in non-specific interstitial pneumonia. Thorax 2011; 66: 61-65.

33. Fujimoto K, Taniguchi H, Johkoh T, Kondoh $\mathrm{Y}$, Ichikado K, Sumikawa H, Ogura T, Kataoka K, Endo T, Kawaguchi A, Muller NL. Acute exacerbation of idiopathic pulmonary fibrosis: high-resolution CT scores predict mortality. Eur Radiol 2012; 22: 83-92. 
34. Sundaram B, Gross BH, Oh E, Muller N, Myles JD, Kazerooni EA. Reader accuracy and confidence in diagnosing diffuse lung disease on high-resolution computed tomography of the lungs: impact of sampling frequency. Acta Radiol 2008; 49: 870-875.

35. Walsh SL, Wells AU, Sverzellati N, Keir GJ, Calandriello L, Antoniou KM, Copley SJ, Devaraj A, Maher TM, Renzoni E, Nicholson AG, Hansell DM. An integrated clinicoradiological staging system for pulmonary sarcoidosis: a case-cohort study. Lancet Respir Med 2014; 2: 123-130.

36. Goh NS, Desai SR, Veeraraghavan S, Hansell DM, Copley SJ, Maher TM, Corte TJ, Sander CR, Ratoff J, Devaraj A, Bozovic G, Denton CP, Black CM, du Bois RM, Wells AU. Interstitial lung disease in systemic sclerosis: a simple staging system. Am J Respir Crit Care Med 2008; 177: 1248-1254.

37. Ley B, Ryerson CJ, Vittinghoff E, Ryu JH, Tomassetti S, Lee JS, Poletti V, Buccioli M, Elicker BM, Jones KD, King TE, Jr., Collard HR. A multidimensional index and staging system for idiopathic pulmonary fibrosis. Ann Intern Med 2012; 156: 684691.

38. Rodriguez LH, Vargas PF, Raff U, Lynch DA, Rojas GM, Moxley DM, Newell JD. Automated discrimination and quantification of idiopathic pulmonary fibrosis from normal lung parenchyma using generalized fractal dimensions in high-resolution computed tomography images. Acad Radiol 1995; 2: 10-18.

39. Kim HJ, Brown MS, Chong D, Gjertson DW, Lu P, Kim HJ, Coy H, Goldin JG. Comparison of the quantitative CT imaging biomarkers of idiopathic pulmonary 
fibrosis at baseline and early change with an interval of 7 months. Acad Radiol 2015; 22: 70-80.

40. Best AC, Meng J, Lynch AM, Bozic CM, Miller D, Grunwald GK, Lynch DA. Idiopathic pulmonary fibrosis: physiologic tests, quantitative CT indexes, and CT visual scores as predictors of mortality. Radiology 2008; 246: 935-940.

41. Uppaluri R, Mitsa T, Sonka M, Hoffman EA, McLennan G. Quantification of pulmonary emphysema from lung computed tomography images. Am J Respir Crit Care Med 1997; 156: 248-254.

42. Uppaluri R, Hoffman EA, Sonka M, Hunninghake GW, McLennan G. Interstitial lung disease: A quantitative study using the adaptive multiple feature method. Am J Respir Crit Care Med 1999; 159: 519-525.

43. Uppaluri R, Hoffman EA, Sonka M, Hartley PG, Hunninghake GW, McLennan G. Computer recognition of regional lung disease patterns. Am J Respir Crit Care Med 1999; 160: 648-654.

44. Xu Y, Sonka M, McLennan G, Guo J, Hoffman EA. MDCT-based 3-D texture classification of emphysema and early smoking related lung pathologies. IEEE Trans Med Imaging 2006; 25: 464-475.

45. Xu Y, van Beek EJ, Hwanjo Y, Guo J, McLennan G, Hoffman EA. Computer-aided classification of interstitial lung diseases via MDCT: 3D adaptive multiple feature method (3D AMFM). Acad Radiol 2006; 13: 969-978.

46. Salisbury ML, Lynch DA, van Beek EJ, Kazerooni EA, Guo J, Xia M, Murray S, Anstrom KJ, Yow E, Martinez FJ, Hoffman EA, Flaherty KR, Investigators IP. Idiopathic Pulmonary Fibrosis: The Association between the Adaptive Multiple 
Features Method and Fibrosis Outcomes. Am J Respir Crit Care Med 2017; 195 : 921-929.

47. Sieren JP, Newell JD, Jr., Barr RG, Bleecker ER, Burnette N, Carretta EE, Couper D, Goldin J, Guo J, Han MK, Hansel NN, Kanner RE, Kazerooni EA, Martinez FJ, Rennard S, Woodruff PG, Hoffman EA, Group SR. SPIROMICS Protocol for Multicenter Quantitative Computed Tomography to Phenotype the Lungs. Am J Respir Crit Care Med 2016; 194: 794-806.

48. Zavaletta VA, Bartholmai BJ, Robb RA. High resolution multidetector CT-aided tissue analysis and quantification of lung fibrosis. Acad Radiol 2007; 14: 772-787. 49. Raghunath S RS, Karwoski RA, Bruesewitz MR, McCollough CH, Bartholmai BJ, Robb RA. Landscaping the effect of CT reconstruction parameters: Robust Interstitial Pulmonary Fibrosis quantitation. Proceedings - International Symposium on Biomedical Imaging 2013: 374-377.

50. Foley F RS, Rajagopalan S, Karwoski R, Maldonado F, Bartholmai B, Peikert T. Computer-aided Lung Informatics for Pathology Evaluation and Rating (caliper) Analysis of Chest Ct to Detect Histologically Proven Emphysema. Am J Respir Crit Care Med 2016; 193: A6613.

51. Jacob J, Bartholmai BJ, Rajagopalan S, Kokosi M, Nair A, Karwoski R, Raghunath SM, Walsh SL, Wells AU, Hansell DM. Automated Quantitative Computed Tomography Versus Visual Computed Tomography Scoring in Idiopathic Pulmonary Fibrosis: Validation Against Pulmonary Function. J Thorac Imaging 2016; 31: 304-311. 
52. Jacob J, Bartholmai BJ, Rajagopalan S, Kokosi M, Maher TM, Nair A, Karwoski R, Renzoni E, Walsh SLF, Hansell DM, Wells AU. Functional and prognostic effects when emphysema complicates idiopathic pulmonary fibrosis. Eur Respir J 2017; 50.

53. Moua T RS, Rajagopalan S, Karwoski R, Bartholmai B, Ryu JH, Robb R, Maldonado F. Can progression of fibrosis as assessed by computer-aided lung informatics for pathology evaluation and rating (CALIPER) predict outcomes in patients With Idiopathic Pulmonary Fibrosis? Chest 2011; 140: 1041A.

54. Bartholmai BJ, Raghunath S, Karwoski RA, Moua T, Rajagopalan S, Maldonado F, Decker PA, Robb RA. Quantitative computed tomography imaging of interstitial lung diseases. J Thorac Imaging 2013; 28: 298-307.

55. Jacob J, Bartholmai BJ, Rajagopalan S, Kokosi M, Egashira R, Brun AL, Nair A, Walsh SLF, Karwoski R, Wells AU. Serial automated quantitative CT analysis in idiopathic pulmonary fibrosis: functional correlations and comparison with changes in visual CT scores. Eur Radiol 2018; 28: 1318-1327.

56. Raghunath S, Rajagopalan S, Karwoski RA, Maldonado F, Peikert T, Moua T, Ryu $\mathrm{JH}$, Bartholmai BJ, Robb RA. Quantitative stratification of diffuse parenchymal lung diseases. PLoS One 2014; 9: e93229.

57. Jacob J, Bartholmai BJ, Rajagopalan S, Brun AL, Egashira R, Karwoski R, Kokosi M, Wells AU, Hansell DM. Evaluation of computer-based computer tomography stratification against outcome models in connective tissue disease-related interstitial lung disease: a patient outcome study. BMC Med 2016; 14: 190. 
58. Van Den Blink B BB, Wijsenbeek M, Miedema J, Rajagopalan S, Westmore M, Lammering K, Wapenaar M. Raghu G, Richeldi L. Automated quantitative imaging correlates with lung function and exercise tolerance in patients with idiopathic pulmonary fibrosis. QJM 2016: S57.

59. Chong DY, Kim HJ, Lo P, Young S, McNitt-Gray MF, Abtin F, Goldin JG, Brown MS. Robustness-Driven Feature Selection in Classification of Fibrotic Interstitial Lung Disease Patterns in Computed Tomography Using 3D Texture Features. IEEE Trans Med Imaging 2016; 35: 144-157.

60. Brown MS, McNitt-Gray MF, Pais R, Shah SK, Qing P, Da Costa I, Aberle DR, Goldin JG. CAD in clinical trials: current role and architectural requirements. Comput Med Imaging Graph 2007; 31: 332-337.

61. Kim GJ BM, Weigt S, Belperio JA, Goldin, JG. Prediction of IPF Using Early Changes in Quantitative Imaging Patterns Using High Resolution Computed Tomography. Am J Respir Crit Care Med 2016; 193: A2706.

62. Coates A NA. Learning feature representations with k-means. In Neural networks: Tricks of the trade. Berlin: Springer; 2012. p. 561-580.

63. Humphries S ORT, Sundy JS, Zhang JJ, Gong Q, Bayly S, Sood R, Raghu G, Lynch DA. Change In CT-Derived Fibrosis Score Correlates With Lung Function Progression In A Clinical Trial Population With Idiopathic Pulmonary Fibrosis. Am J Respir Crit Care Med 2017; 195: A6783.

64. Hajian B, De Backer J, Vos W, Van Holsbeke C, Clukers J, De Backer W. Functional respiratory imaging (FRI) for optimizing therapy development and patient care. Expert Rev Respir Med 2016; 10: 193-206. 
65. De Backer LA, Vos W, De Backer J, Van Holsbeke C, Vinchurkar S, De Backer W. The acute effect of budesonide/formoterol in COPD: a multi-slice computed tomography and lung function study. Eur Respir J 2012; 40: 298-305.

66. De Backer JW, Vos WG, Vinchurkar SC, Claes R, Drollmann A, Wulfrank D, Parizel PM, Germonpre P, De Backer W. Validation of computational fluid dynamics in CT-based airway models with SPECT/CT. Radiology 2010; 257: 854-862.

67. Tahir BA, Van Holsbeke C, Ireland RH, Swift AJ, Horn FC, Marshall H, Kenworthy JC, Parra-Robles J, Hartley R, Kay R, Brightling CE, De Backer J, Vos W, Wild JM. Comparison of CT-based Lobar Ventilation with 3He MR Imaging Ventilation Measurements. Radiology 2016; 278: 585-592.

68. Hajian B, De Backer J, Vos W, Van Holsbeke C, Ferreira F, Quinn DA, Hufkens A, Claes R, De Backer W. Pulmonary vascular effects of pulsed inhaled nitric oxide in COPD patients with pulmonary hypertension. Int J Chron Obstruct Pulmon Dis 2016; 11: 1533-1541.

69. De Backer J, Van Holsbeke C, Vos W, Vinchurkar S, Dorinsky P, Rebello J, Mangale M, Hajian B, De Backer W. Assessment of lung deposition and analysis of the effect of fluticasone/salmeterol hydrofluoroalkane (HFA) pressurized metered dose inhaler (pMDI) in stable persistent asthma patients using functional respiratory imaging. Expert Rev Respir Med 2016; 10: 927-933.

70. Lanclus M, Porter S, Mignot B, Kouchakji E, Gorina E, Van Holsbeke C, De Backer J, Vos W, Clukers J, De Backer W, Goldin J, Mussche C. Late Breaking Abstract - Assessment of disease progression in IPF patients using Functional Respiratory Imaging (FRI). European Respiratory Journal 2017; 50. 
71. Mussche C, Van Holsbeke C, De Backer J, Vos W, Lanclus M, Mignot B, De Backer W, Clukers J, Porter S, Kouchakji E, Gorina E, Goldin J. Late Breaking Abstract Responder phenotyping using functional respiratory imaging (FRI) in IPF patients treated with anti-CGTG monoclonal antibody FG3019. European Respiratory Journal 2017; 50.

72. Hansell DM, Bankier AA, MacMahon H, McLoud TC, Muller NL, Remy J. Fleischner Society: glossary of terms for thoracic imaging. Radiology 2008; 246: 697-722.

73. Muller NL, Guerry-Force ML, Staples CA, Wright JL, Wiggs B, Coppin C, Pare P, Hogg JC. Differential diagnosis of bronchiolitis obliterans with organizing pneumonia and usual interstitial pneumonia: clinical, functional, and radiologic findings. Radiology 1987; 162: 151-156.

74. Muller NL, Miller RR, Webb WR, Evans KG, Ostrow DN. Fibrosing alveolitis: CTpathologic correlation. Radiology 1986; 160: 585-588.

75. Muller NL, Staples CA, Miller RR, Vedal S, Thurlbeck WM, Ostrow DN. Disease activity in idiopathic pulmonary fibrosis: CT and pathologic correlation. Radiology 1987; 165: 731-734.

76. Silver SF, Muller NL, Miller RR, Lefcoe MS. Hypersensitivity pneumonitis: evaluation with CT. Radiology 1989; 173: 441-445.

77. Jacob J, Bartholmai BJ, Rajagopalan S, Kokosi M, Nair A, Karwoski R, Walsh SL, Wells AU, Hansell DM. Mortality prediction in idiopathic pulmonary fibrosis: evaluation of computer-based CT analysis with conventional severity measures. Eur Respir J 2017; 49. 
78. Jacob J, Bartholmai BJ, Egashira R, Brun AL, Rajagopalan S, Karwoski R, Kokosi M, Hansell DM, Wells AU. Chronic hypersensitivity pneumonitis: identification of key prognostic determinants using automated CT analysis. BMC Pulm Med 2017; $17: 81$.

79. Washko GR, Lynch DA, Matsuoka S, Ross JC, Umeoka S, Diaz A, Sciurba FC, Hunninghake GM, San Jose Estepar R, Silverman EK, Rosas IO, Hatabu H. Identification of early interstitial lung disease in smokers from the COPDGene Study. Acad Radiol 2010; 17: 48-53.

80. Putman RK, Hatabu H, Araki T, Gudmundsson G, Gao W, Nishino M, Okajima Y, Dupuis J, Latourelle JC, Cho MH, El-Chemaly S, Coxson HO, Celli BR, Fernandez IE, Zazueta OE, Ross JC, Harmouche R, Estepar RS, Diaz AA, Sigurdsson S, Gudmundsson EF, Eiriksdottir G, Aspelund T, Budoff MJ, Kinney GL, Hokanson JE, Williams MC, Murchison JT, MacNee W, Hoffmann U, O'Donnell CJ, Launer LJ, Harrris TB, Gudnason V, Silverman EK, O'Connor GT, Washko GR, Rosas IO, Hunninghake GM, Evaluation of CLtIPSEI, Investigators CO. Association Between Interstitial Lung Abnormalities and All-Cause Mortality. JAMA 2016; 315: 672-681.

81. Ash SY, Harmouche R, Putman RK, Ross JC, Diaz AA, Hunninghake GM, Onieva Onieva J, Martinez FJ, Choi AM, Lynch DA, Hatabu H, Rosas IO, San Jose Estepar R, Washko GR, Investigators CO. Clinical and Genetic Associations of Objectively Identified Interstitial Changes in Smokers. Chest 2017; 152: 780-791. 
82. Fuld MK, Grout RW, Guo J, Morgan JH, Hoffman EA. Systems for lung volume standardization during static and dynamic MDCT-based quantitative assessment of pulmonary structure and function. Acad Radiol 2012; 19: 930-940.

83. Obuchowski NA, Reeves AP, Huang EP, Wang XF, Buckler AJ, Kim HJ, Barnhart HX, Jackson EF, Giger ML, Pennello G, Toledano AY, Kalpathy-Cramer J, Apanasovich TV, Kinahan PE, Myers KJ, Goldgof DB, Barboriak DP, Gillies RJ, Schwartz LH, Sullivan DC, Algorithm Comparison Working G. Quantitative imaging biomarkers: a review of statistical methods for computer algorithm comparisons. Stat Methods Med Res 2015; 24: 68-106.

84. Matsumoto AJ, Bartholmai BJ, Wylam ME. Comparison of Total Lung Capacity Determined by Plethysmography With Computed Tomographic Segmentation Using CALIPER. J Thorac Imaging 2017; 32: 101-106.

85. Jacob J, Bartholmai BJ, Rajagopalan S, Karwoski R, Nair A, Walsh SLF, Barnett J, Cross G, Judge EP, Kokosi M, Renzoni E, Maher TM, Wells AU. Likelihood of pulmonary hypertension in patients with idiopathic pulmonary fibrosis and emphysema. Respirology 2017.

86. Maldonado F, Moua T, Rajagopalan S, Karwoski RA, Raghunath S, Decker PA, Hartman TE, Bartholmai BJ, Robb RA, Ryu JH. Automated quantification of radiological patterns predicts survival in idiopathic pulmonary fibrosis. Eur Respir J 2014; 43: 204-212.

87. De Giacomi F, Raghunath S, Karwoski R, Bartholmai BJ, Moua T. Short-term Automated Quantification of Radiologic Changes in the Characterization of 
Idiopathic Pulmonary Fibrosis Versus Nonspecific Interstitial Pneumonia and Prediction of Long-term Survival. J Thorac Imaging 2018; 33: 124-131.

88. van den Blink B, Dillingh MR, Ginns LC, Morrison LD, Moerland M, Wijsenbeek M, Trehu EG, Bartholmai BJ, Burggraaf J. Recombinant human pentraxin-2 therapy in patients with idiopathic pulmonary fibrosis: safety, pharmacokinetics and exploratory efficacy. Eur Respir J 2016; 47: 889-897.

89. Raghu G, Scholand MB, de Andrade J, Lancaster L, Mageto Y, Goldin J, Brown KK, Flaherty KR, Wencel M, Wanger J, Neff T, Valone F, Stauffer J, Porter S. FG3019 anti-connective tissue growth factor monoclonal antibody: results of an open-label clinical trial in idiopathic pulmonary fibrosis. Eur Respir J 2016; 47: $1481-1491$.

90. Humphries SM, Yagihashi K, Huckleberry J, Rho BH, Schroeder JD, Strand M, Schwarz MI, Flaherty KR, Kazerooni EA, van Beek EJR, Lynch DA. Idiopathic Pulmonary Fibrosis: Data-driven Textural Analysis of Extent of Fibrosis at Baseline and 15-Month Follow-up. Radiology 2017; 285: 270-278. 


\section{Table 1.}

\begin{tabular}{|c|c|}
\hline QCT Method & Key findings in IPF \\
\hline $\begin{array}{c}\text { Histogram/Kurtosis } \\
\text { analysis }\end{array}$ & $\begin{array}{l}\text { 1. Kurtosis and skewness on histogram analysis are } \\
\text { associated with the changes in physiology and overall } \\
\text { survival in patients with IPF }(15,40) \text {. }\end{array}$ \\
\hline AMFM & $\begin{array}{l}\text { 1. AMFM was shown to be superior to earlier quantitative CT- } \\
\text { based metrics including mean lung density and histogram- } \\
\text { based metrics in distinguishing between normal } \\
\text { parenchyma and parenchyma from IPF or sarcoid patients } \\
\text { (42). } \\
\text { 2. AMFM enhanced with 3D texture and a support vector } \\
\text { machine classifier was shown to have a better than } 90 \% \\
\text { sensitivity and specificity in classifying } 5 \text { simultaneous } \\
\text { regional textures including emphysema, ground glass, and } \\
\text { honeycombing (44, } 45 \text { ). } \\
\text { 3. AMFM measurement of baseline extent of mixed ground } \\
\text { glass + reticular densities (GGR) predicts subsequent } \\
\text { disease progression (death, hospitalization, or }>10 \% \text { FVC } \\
\text { decline), and post-baseline GGR change correlates with } \\
\text { post-baseline FVC change (46). }\end{array}$ \\
\hline CALIPER & $\begin{array}{l}\text { 1. CALIPER ILD variables and vessel-related structures can } \\
\text { predict lung function tests and improve on visual CT scores } \\
(51,84) \text {. } \\
\text { 2. Vessel-related structure scores better predict mortality than } \\
\text { baseline visual CT scores in IPF (77). } \\
\text { 3. Compared to IPF alone patients with combined fibrosis and } \\
\text { emphysema do not have worsened outcomes (52) or } \\
\text { increased likelihoods of pulmonary hypertension (85) } \\
\text { beyond that explained by extents of ILD and emphysema. } \\
\text { 4. CALIPER ILD variables and vessel-related structures better } \\
\text { predict lung function decline than longitudinal visual CT } \\
\text { scores (55). } \\
\text { 5. Change in CALIPER features predict survival (86). } \\
\text { 6. Change in CALIPER features can help distinguish between } \\
\text { IPF and NSIP in difficult to diagnose cases (87). } \\
\text { 7. Stability of CALIPER normal lung parenchymal volumes in a } \\
\text { phase I therapeutic study (88). }\end{array}$ \\
\hline
\end{tabular}




\begin{tabular}{|c|c|}
\hline QLF/QILD & $\begin{array}{l}\text { 1. QLF/QILD measurements have been developed to } \\
\text { overcome the variations due to CT technical parameters } \\
\text { from the multi-center trials (59). } \\
\text { 2. QLF scores has been evaluated as the part of the analytic } \\
\text { validation with visual scores (59). } \\
\text { 3. QLF scores have been clinically validated after locking the } \\
\text { algorithm (60,61). } \\
\text { 4. An automated QLF/QILD system has been implemented } \\
\text { and validated to be ready for clinical trials, which is an } \\
\text { important part prior to the clinical utilities (60). } \\
\text { 5. Changes in QLF and QILD scores were associated with the } \\
\text { changes in FVC, FEV1, and DLCO (surrogate outcomes) } \\
\text { (39, } 89) \text {. } \\
\text { 6. Week } 24 \text { changes in QLF predict FVC changes in week } 36 \\
\text { and } 48 \text { (61). } \\
\text { 7. Used in } 6 \text { phase II trials as secondary or exploratory } \\
\text { outcomes and } 1 \text { phase IIIb trial as a primary endpoint } \\
\text { (NCT01979952). }\end{array}$ \\
\hline DTA & $\begin{array}{l}\text { 1. DTA fibrosis is associated with visual assessment and } \\
\text { baseline lung function and change in DTA fibrosis extent on } \\
\text { sequential scans is associated with change in function (90). } \\
\text { 2. Greater baseline DTA score is associated with increased } \\
\text { risk of disease progression and all-cause hospitalization } \\
\text { (63). } \\
\text { 3. Subjects with disease progression at visual assessment had } \\
\text { greater DTA fibrosis extent and poorer lung function at } \\
\text { baseline and had greater rates of change in these indexes } \\
\text { over the follow-up period (90). } \\
\text { 4. In two IPF clinical trial populations with sequential scans, an } \\
\text { increase of 5.5\% in DTA fibrosis extent was associated with } \\
\text { progression determined as } 5 \% \text { decline in FVC (unpublished } \\
\text { data). }\end{array}$ \\
\hline FRI & $\begin{array}{l}\text { 1. Lobe volumes decrease with progressing disease with lower } \\
\text { lobes more affected than upper lobes for all FVC values } \\
(71) \text {. } \\
\text { 2. Airway volumes, corrected for lung volumes, increase with } \\
\text { progressing disease with the increase driven by pressure } \\
\text { redistribution and traction bronchiectasis }(71) \text {. } \\
\text { 3. Lobe volumes and airway volumes could already be } \\
\text { severely affected by IPF even when FVC is normal (71). } \\
\text { 4. Baseline FRI parameters have the potential to predict } \\
\text { treatment success (70). } \\
\text { 5. Endpoints describing changes in regional anatomical } \\
\text { structure and function have the potential to be more } \\
\text { sensitive than FVC resulting in smaller and shorter clinical } \\
\text { trials }(71) \text {. }\end{array}$ \\
\hline
\end{tabular}




\section{Figure Legend}

Figure 1. Two patients with mild and severe IPF (FVC 65\%, and 47\%, respectively):

kurtosis measures are 5.00, and 0.41 in subjects with mild and severe IPF, respectively. Corresponding skewness measures are 1.48 , and 0.80 . [Reprinted with permission from Kim et al Acad Radiol. 2015]

Figure 2. Four-panel sets serving as examples of regional AMFM-derived results for two patients with IPF. Unlabeled dorsal (top) and mid (bottom) level coronal sections are shown in the left panels obtained from a subject with lower (top set) and a subject with higher (bottom set) proportion of lung voxels/regions characterized as representing a ground glass reticular (GGR) texture pattern. The right panels show regional transparent color overlays representing the parenchymal characteristic determined by the AMFM from the regional image texture. A higher proportion of lung characterized as GGR on a baseline HRCT was associated with increased risk of disease progression among IPF subjects enrolled in a clinical therapeutic trial. Colors represent: Ground Glass (Green), Normal (White), Ground Glass-Reticular (Blue), Bronchovascular (Brown), and Honeycomb (Yellow).

Figure 3. Axial CT image of UIP with CALIPER characterization. Top: Reticulation, ground glass opacity and traction bronchiectasis are visible in both lower lobes and the anterior right middle lobe, with a honeycomb cyst visible in the left lower lobe. Middle: Color overlay image highlighting parenchymal features characterized by CALIPER: normal lung (light and dark green) surrounds areas of ground glass opacity (yellow), 
reticulation (orange) and the left lower lobe honeycomb cyst (red). Bottom: Pulmonary vessel volume quantified by CALIPER is an analytic feature that includes pulmonary arteries, veins, and other small branching/linear structures in areas that contain more severe fibrosis.

Figure 4. Coronal and sagittal CT images at baseline and 12 months with QLF characterization: Top: original images of coronal (left) and sagittal (right) images, Bottom: annotated coronal and sagittal HRCT images with the classification of quantitative lung fibrosis (QLF) (blue +red). Center: a paired set of 5D plots with 3 dimensional locations, QLF scores, and temporal information at baseline and 12 months, where the circle size indicates QLF score and an orange circle indicates the most severe lobe (left lower lobe). QLF increased from $12 \%$ to $17 \%$ in the left lower lobe. In whole lung, QLF increased from $9 \%$ to $14 \%$ over 12 months.

Figure 5. Axial chest CT section of a subject with UIP (left). Classification results (right) show regions classified as normal (green), airway (blue), reticular abnormality (yellow) and honeycombing (red). DTA score is the percentage of lung volume occupied by reticular abnormality or honeycombing.

Figure 6. Patient specific reconstruction of fibrosis (green), distal airways (blue), central airways (gray), emphysema (black) and blood vessels (red) using Functional Respiratory Imaging (FRI). 


\section{Figure 1}

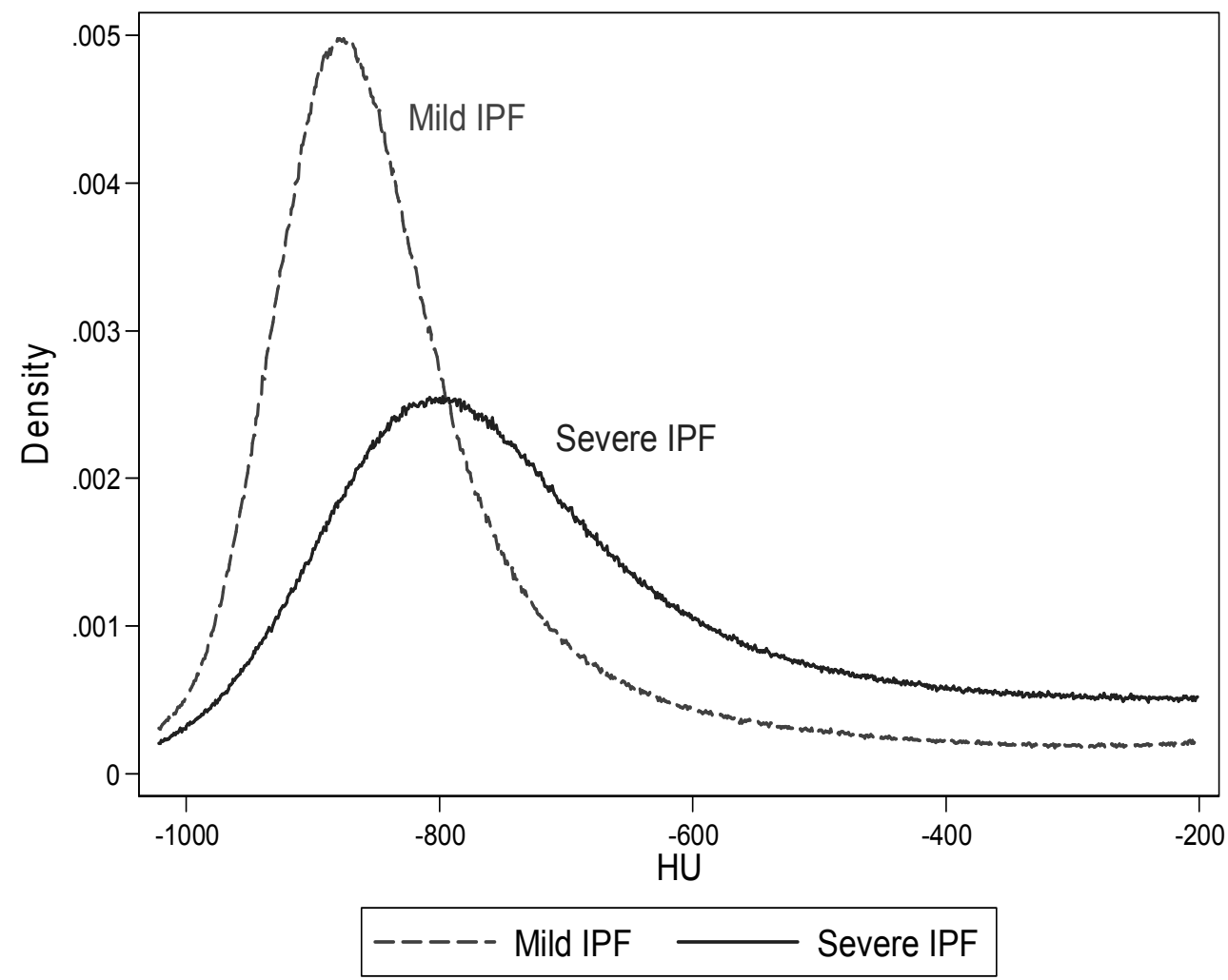


Figure 2

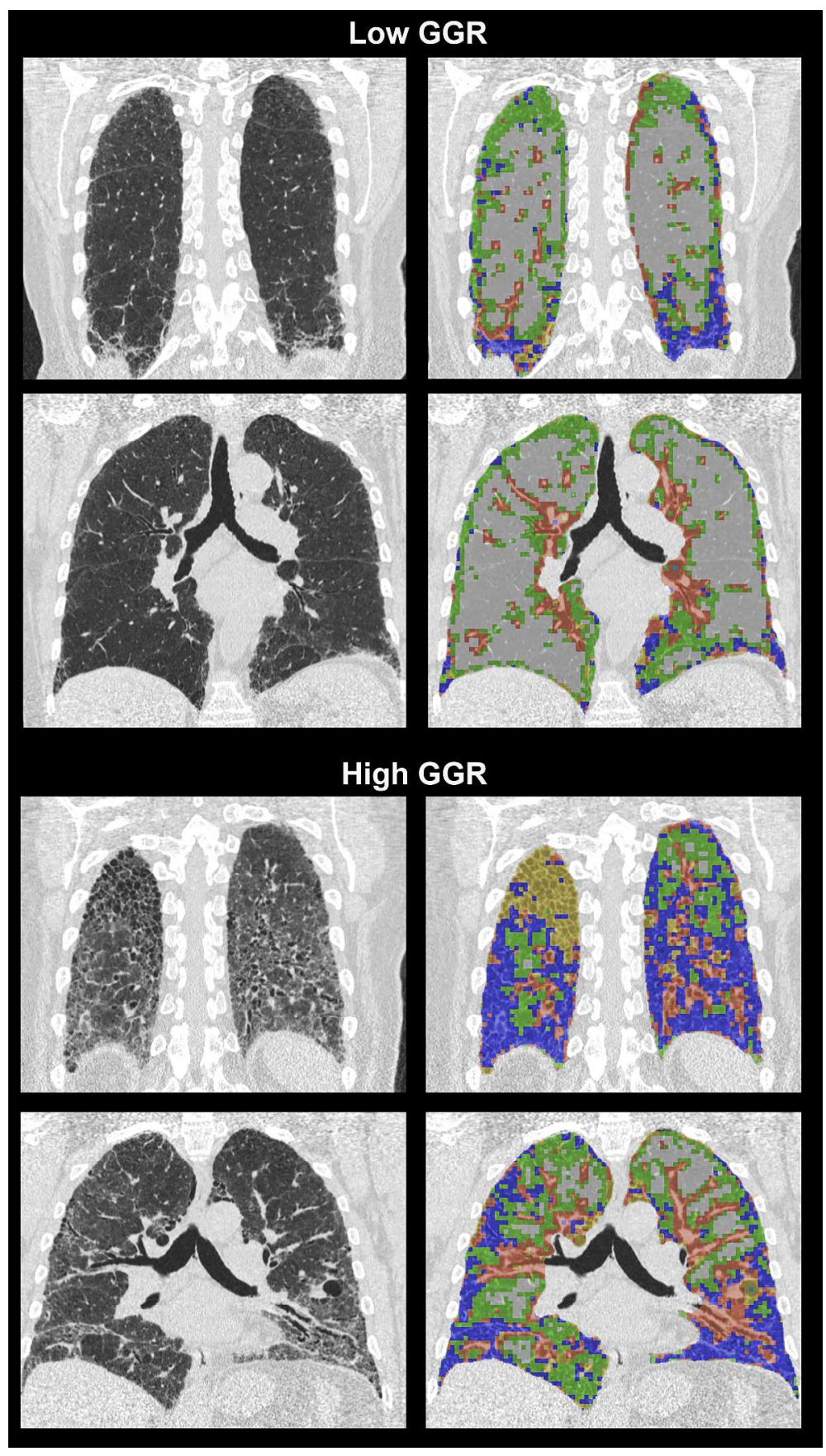


Figure 3

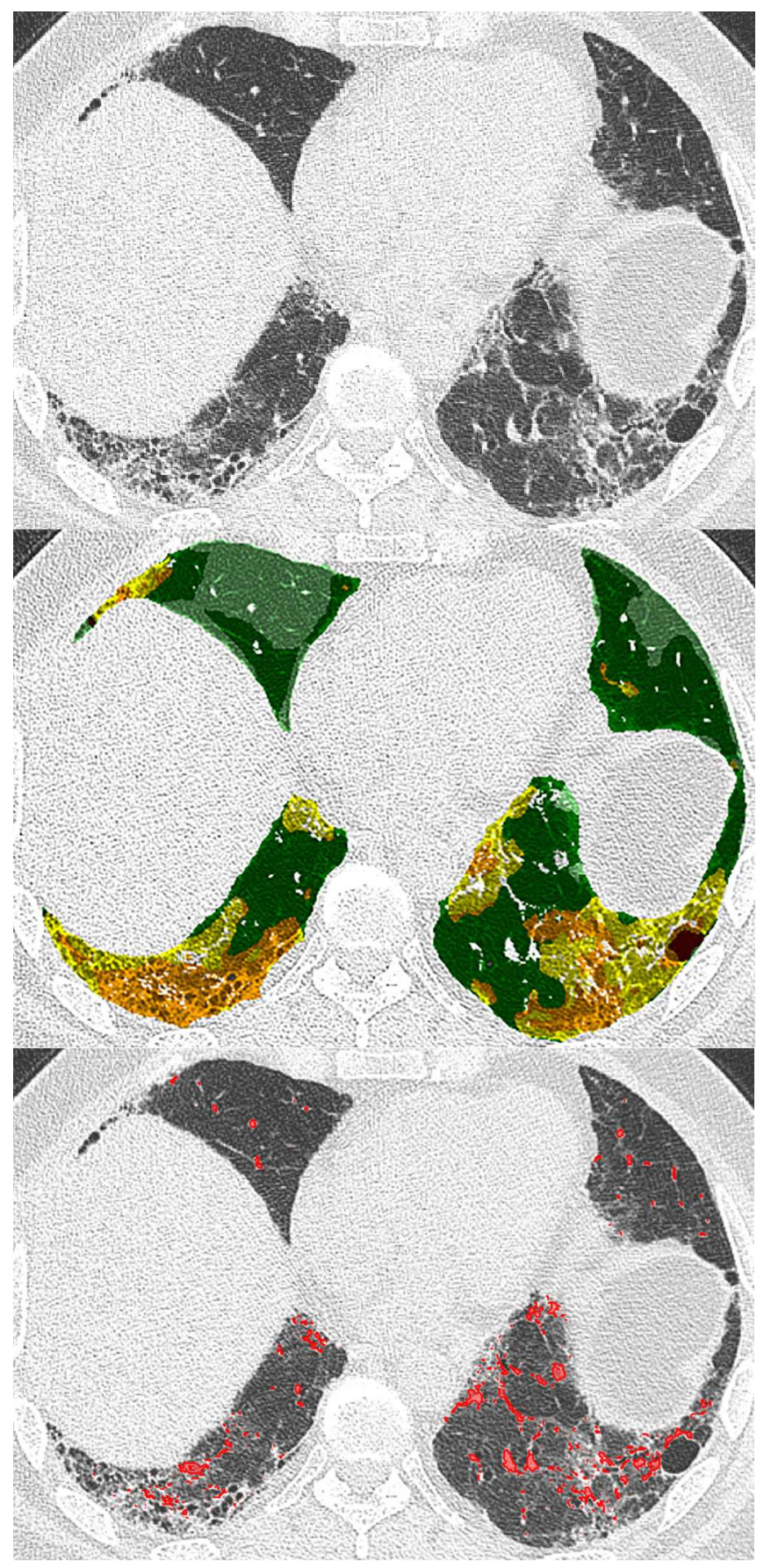


Figure 4

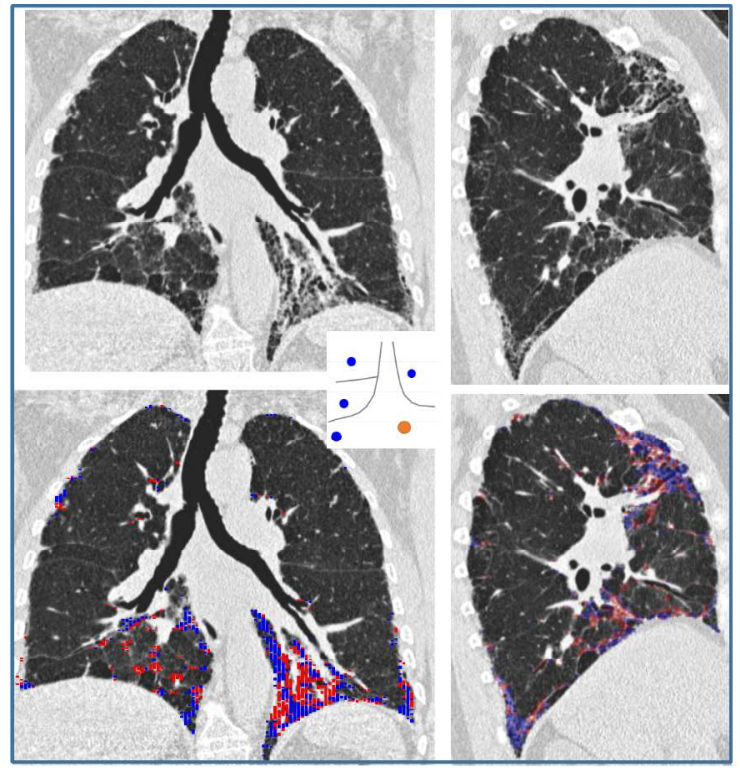

Baseline

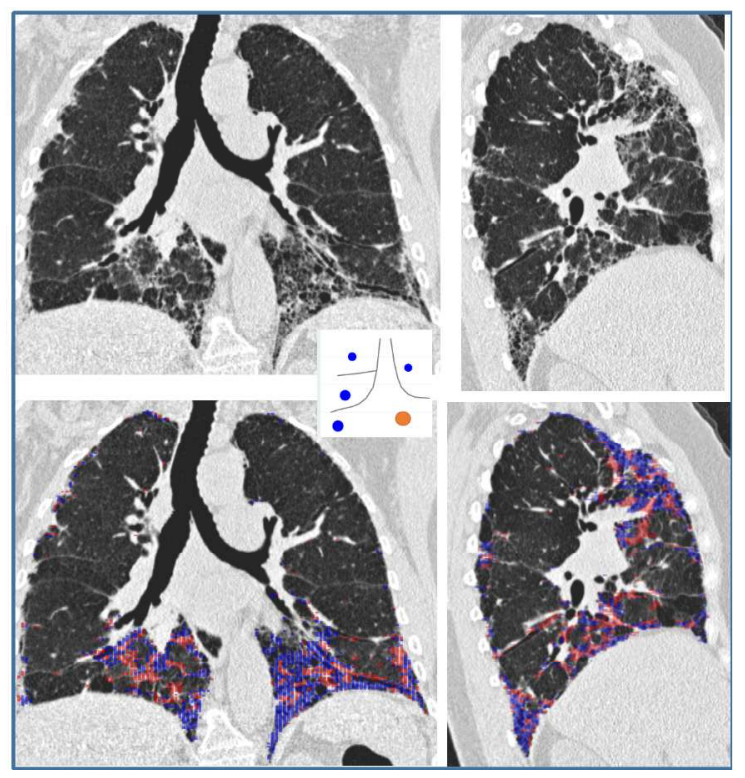

12 months

Figure 5

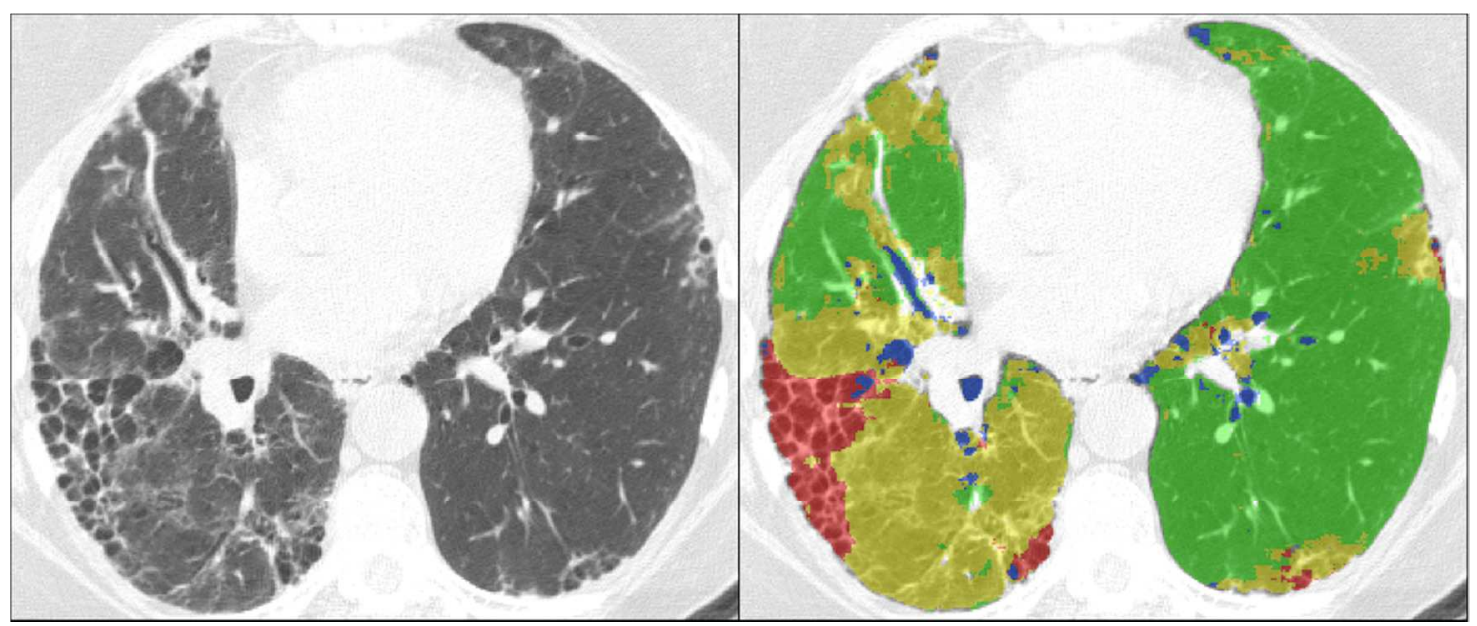




\section{Figure 6}

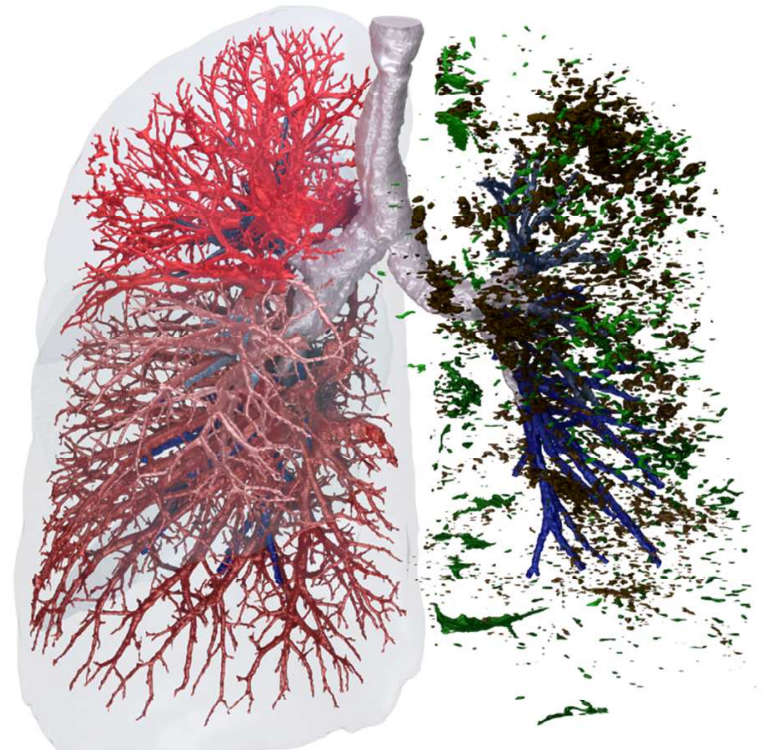

